\title{
Further Studies on Leptospiral Genus-specific Antigen: Its Ultrastructure and Immunochemistry
}

\author{
By A. PALIT, R. C. HAMILTON AND J. GULASEKHARAM \\ The Commonwealth Serum Laboratories, Parkville, Victoria, Australia, 3052
}

(Received 25 October I973; revised 2 January 1974)

\begin{abstract}
SUMMARY
Fifty per cent ethanol treatment removed most of the outer envelope of serotype biflexa, strain Patoc I. The trilaminar outer envelope was recovered from the $50 \%$ ethanol supernatant by raising the ethanol concentration to $90 \%(\mathrm{v} / \mathrm{v})$. Five and even seven layers in the outer envelopes were seen. The $90 \%$ ethanol precipitate contained the erythrocyte-sensitizing substance (ESS). An anti-ESS serum was reactive in leptospiral agglutination, haemagglutination and in Ouchterlony's double diffusion tests. Electron microscopic examination revealed the presence of stripping and agglutination of stripped or unstripped outer envelopes of healthy Patoc I cells in the presence of anti-ESS serum. The $90 \%$ ethanol precipitate of Patoc I organisms contained polysaccharide, lipid, protein, amino sugars and 16 different amino acids. The suggestion that the genus-specific leptospiral erythrocyte-sensitizing substance is, or is associated with, the outer envelope of strain Patoc I is discussed.
\end{abstract}

\section{INTRODUCTION}

Tightly coiled leptospires have an outer envelope or enveloping sheath (World Health Organization, 1972; as described by Nauman, Holt \& Cox, 1969; Anderson \& Johnson, 1968; Pillot \& Ryter, 1965; Ritchie \& Ellinghausen, 1965). Between the outer envelope and the inner protoplasmic cylinder lie two axial filaments each of which is attached to either end of the protoplasmic cylinder. The presence of more than two axial filaments has also been reported (Chang \& Faine, 1970). Immune disruption and removal of pathogenic and non-pathogenic leptospiral envelopes mediated by specific antibodies and complement (Anderson \& Johnson, 1968) allowed lysozyme to act on the protoplasmic cylinder. Recently Auran, Johnson \& Ritzi (1972) demonstrated that the outer envelope of serotype canicola Hond Utrecht IV protected hamsters against challenge infection with homologous virulent cultures.

We now report that most of the outer envelope of serotype biflexa, Patoc I may be removed by the $50 \%$ ethanol extraction method (Chang \& McComb, 1954). A precipitate which contains the erythrocyte-sensitizing substance may be obtained by raising the concentration of ethanol to $90 \%(\mathrm{v} / \mathrm{v})$. A suspension of erythrocytes sensitized with this substance acts as a genus-specific haemagglutination antigen when tested against a wide variety of human and bovine leptospiral antisera (Palit \& Gulasekharam, 1973). We have further studied the $90 \%$ ethanol-precipitated antigen, including its ultrastructure, serology and chemical aspects. 


\section{METHODS}

Preparation of the extract containing the genus-specific ESS. The strain of Leptospira employed in this study was Patoc I of the non-pathogenic biflexa complex. Its growth, the harvesting of organisms and ethanol extraction procedures to obtain the ESS have been detailed by Palit \& Gulasekharam (1973).

Preparation of anti-ESS serum. Washed sheep red cells were coated with the optimum dilution of the antigen (Palit \& Gulasekharam, 1973). The sensitized red cells were then

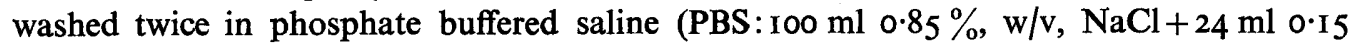
$\mathrm{M}-\mathrm{KH}_{2} \mathrm{PO}_{4}+76 \mathrm{ml} \mathrm{0} \cdot \mathrm{I}_{5} \mathrm{M}-\mathrm{Na}_{2} \mathrm{HPO}_{4}$ ), $\mathrm{pH} 7 \cdot 2$ (Carpenter, ${ }_{7965)}$, and a $\mathrm{I} \%$ suspension of the cells was used to immunize healthy rabbits which had been shown to be free of Patoc I antibodies [tested by passive haemagglutination (h.a.) and microscopic agglutination (m.a.) tests]. Each rabbit received one intravenous injection every $4^{\text {th }}$ day with increasing doses of $2 \mathrm{ml}, 3 \mathrm{ml}$ and $4 \mathrm{ml}$ respectively, and was bled by cardiac puncture 7 days after the last injection. Anti-ESS serum was inactivated at $56^{\circ} \mathrm{C}$ for $30 \mathrm{~min}$ and then absorbed with washed, packed sheep red cells until the antiserum was free of antibodies to normal sheep red cells. Finally, it was sterilized by filtration through a millipore filter $(0 \cdot 22 \mu \mathrm{m})$ and stored at $-20^{\circ} \mathrm{C}$ in small portions.

Ammonium sulphate precipitation of anti-ESS serum. Five serial precipitations with $33 \%$ saturated ammonium sulphate were carried out on the anti-ESS serum. The precipitated globulin fraction was first dialysed against several changes of $0.85 \%(\mathrm{w} / \mathrm{v}) \mathrm{NaCl}$ solution at $4{ }^{\circ} \mathrm{C}$ and then against distilled water. A precipitate appeared which was removed (Kabat \& Mayer, $1964 a$ ) by centrifuging at $12000 \mathrm{~g}$ for $\mathrm{I} 2 \mathrm{~min}$. The supernatant was finally dialysed against $0.2 \mathrm{M}$-PBS, $\mathrm{pH} 7.5$, sterilized through a millipore filter pad $(0.22 \mu \mathrm{m})$ and stored at $4{ }^{\circ} \mathrm{C}$. The dry weight of the globulin fraction was 12 to $15 \mathrm{mg} / \mathrm{ml}$.

Electron microscopy. For negative staining, a small drop of the sample was placed on a Formvar-coated grid which was then inverted into a drop of $2 \%$ phosphotungstic acid neutralized to $\mathrm{pH}_{7} \cdot 0$. After I min the grid was removed and excess stain blotted off with filter paper. The dry grid was examined.

To provide thin sections, samples were prefixed with $2 \%$ glutaraldehyde (pH 6.0) prepared by mixing equal volumes of $4 \%$ glutaraldehyde solution and $0.2 \mathrm{M}$-phosphate buffer (containing $0.2 \mathrm{M}-\mathrm{Na}_{2} \mathrm{HPO}_{4}$ and $0.2 \mathrm{M}-\mathrm{NaH}_{2} \mathrm{PO}_{4}$ in appropriate proportions). After prefixation the samples were washed with veronal acetate buffer, $\mathrm{pH} 6 \cdot 0$, and fixed by the method of Kellenberger, Ryter \& Séchaud (1958). The agar blocks containing the sample were dehydrated in acetone and embedded in Durcupan (Flüka, Basle, Switzerland) before sectioning. The thin sections were stained with lead citrate (Reynolds, 1963) for $5 \mathrm{~min}$, after which they were examined.

Serology. The microscopic agglutination (m.a.), immunodiffusion in agar gel, the indirect or passive haemagglutination (h.a.) tests and the titration of $90 \%$ ethanol extract for the determination of the optimum erythrocyte sensitizing dilution have been described elsewhere (Palit \& Gulasekharam, 1973; Palit \& Sharma, 1971).

For absorption studies, a portion of the anti-ESS serum was absorbed with the $50 \%(\mathrm{v} / \mathrm{v})$ ethanol-treated, washed Patoc I organisms, while another portion was absorbed with untreated washed Patoc I organisms. Leptospires were grown in Korthof's medium (Alston \& Broom, 1958) containing $10 \%$ rabbit serum for 8 to Io days. Organisms were centrifuged at $14000 \mathrm{~g}$ for $30 \mathrm{~min}$, washed twice in PBS (pH 7.2) and the number of organisms adjusted to $8 \times 10^{9} / \mathrm{ml}$ after direct counting in a counting chamber. Part of this suspension was treated with $50 \%(\mathrm{v} / \mathrm{v})$ ethanol. Ethanol-treated, centrifuged leptospires were washed once 
and suspended in PBS (pH 7.2) to their original concentration. Ethanol-treated leptospiral suspension ( 9 vol.) was added to anti-ESS serum (I vol.). Similarly, 9 vol. of the untreated leptospiral suspension were added to another portion of anti-ESS serum (I vol.). Both these mixtures were allowed to react at $37^{\circ} \mathrm{C}$ for $\mathrm{I} \mathrm{h}$, centrifuged at $14000 \mathrm{~g}$ for $30 \mathrm{~min}$ and the supernatants used separately for h.a. and m.a. tests.

In the treatment of washed leptospires with anti-ESS globulin, equal volumes of antiESS globulin and washed leptospiral suspension (see above) were mixed, and incubated at $37^{\circ} \mathrm{C}$ for $30 \mathrm{~min}$. The reacted mixture was centrifuged at $14000 \mathrm{~g}$ for $30 \mathrm{~min}$, the resulting pellet washed once and resuspended to the volume of the original suspension.

Chemical analyses on the $90 \%$ ethanol precipitate of Patoc I. (i) Carbohydrate determination. Two separate methods were employed: the potassium ferricyanide method of Park \& Johnson (1949) as described by Williams \& Chase (1968), and the indole test as described by Kabat \& Mayer (1964b). D-Glucose was used as a reference standard for both these tests.

(ii) Lipid determination. The sample (I 2 to $16 \mathrm{mg} / \mathrm{ml}$ distilled water) was hydrolysed with $2 \mathrm{M}-\mathrm{HCl}$ in a sealed ampoule for $\mathrm{I} \mathrm{h}$. The hydrolysate was extracted with an equal volume of chloroform:methanol (2:1) mixture. The chloroform layer was separated and dried under vacuum. The dry weight was recorded.

(iii) Protein determination. The micro-Kjeldahl method was used.

(iv) Amino sugar determination. The method of Elson and Morgan was followed as described by Kabat \& Mayer (1964c). D-Glucosamine hydrochloride was used as reference standard.

(v) Paper chromatography. Approximately 12 to $16 \mathrm{mg}$ dry weight quantities of the $90 \%$ ethanol precipitate were suspended in I $\mathrm{ml}$ distilled water and hydrolysed with either $2 \mathrm{M}-\mathrm{H}_{2} \mathrm{SO}_{4}$ or $2 \mathrm{M}-\mathrm{HCl}$ in sealed ampoules in a boiling water bath for 2 and $4 \mathrm{~h}$ respectively. Acid was removed from the $\mathrm{HCl}$ hydrolysate in vacuo over $\mathrm{P}_{2} \mathrm{O}_{5}$ and $\mathrm{NaOH}$ pellets. Acid from the $\mathrm{H}_{2} \mathrm{SO}_{4}$ hydrolysate was removed by barium hydroxide precipitation followed by bubbling $\mathrm{CO}_{2}$ through the supernatant. The clear supernatant from $\mathrm{CO}_{2}$ precipitation was freeze dried. Before spotting on the paper each of the hydrolysates was reconstituted in distilled water to half the original volume. Whatman No. I paper was used in descending chromatography with a mixture of butanol:pyridine: water: acetic acid $(60: 40: 30: 3$, by vol.) as solvent. The developed and dried chromatogram was stained with alkaline silver nitrate (Smith, 1960). Standard sugar solutions were run in parallel with the hydrolysates to identify the various sugars present in the hydrolysates. Standard sugar solutions used were D-galactosamine $\mathbf{H C l}, \mathrm{D}$-glucosamine $\mathrm{HCl}, \mathrm{D}$-glucose, D-galactose, glucuronic acid, galacturonic acid, muramic acid, D-mannose, D-xylose, D-ribose, D-fucose, L-rhamnose and D-arabinose. All these sugars were obtained from Calbiochem, and were chromatographically pure.

(vi) Amino acid and amino sugar determination. Amino acid analysis was by a Beckman (Spinco) model MS amino acid analyser. A sample of $54 \mathrm{mg}$ dry weight of the material was hydrolysed in $1.5 \mathrm{ml} 6 \mathrm{M}-\mathrm{HCl}$ for $24 \mathrm{~h}$ in a sealed ampoule at $110^{\circ} \mathrm{C}$. Acid was removed in vacuo over $\mathrm{P}_{2} \mathrm{O}_{5}$ and $\mathrm{NaOH}$ pellets. Basic amino acids and amino sugars were determined in a short $(15 \mathrm{~cm})$ column whereas acidic and neutral acids were determined in a long ( $1.5 \mathrm{~m}$ ) column.

(vii) Phosphorus determination. The total phosphorus content was determined by the phosphomolybdic method of Lindberg \& Ernster (1956). 


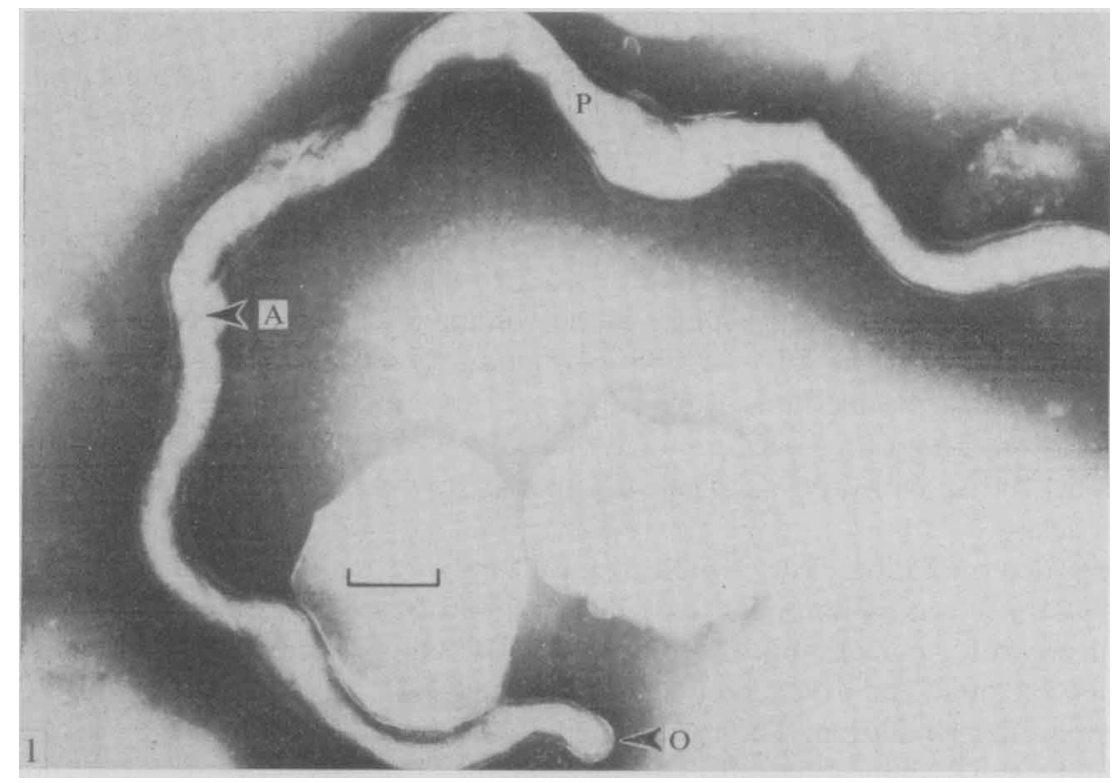

Fig. I. Electron micrograph of negatively-stained healthy Patoc I organism. A, axial filament; $\mathrm{O}$, outer envelope; $\mathrm{P}$, protoplasmic cylinder. Bar marker $0.2 \mu \mathrm{m}$.

\section{RESULTS}

\section{Electron microscopy of normal Patoc I}

The normal washed organism of strain Patoc I consists of a helicoidal protoplasmic cylinder which is surrounded by an outer envelope; between the outer envelope and protoplasmic cylinder lie two axial filaments (Fig. I). Occasionally the outer envelope was lost during the washing process and the axial filament was exposed. When this happened the point of insertion of the axial filament into the protoplasmic cylinder sometimes became evident (Fig. 2). Sections of normal leptospires showed that the outer envelope was a trilaminar membrane, $4.6 \mathrm{~nm}$ (S.D. 0.46, I 18 readings) in thickness (Fig. 3).

\section{Electron microscopy of the sediment of strain Patoc I treated with $50 \%(v / v)$ ethanol}

Treatment of leptospires with $50 \%(\mathrm{v} / \mathrm{v})$ ethanol resulted in the incomplete removal of the outer envelope from the protoplasmic cylinder. Most commonly this outer envelope was composed of three layers, but occasional envelopes composed of seven distinct layers were also observed (Figs. 4, 5). The seven-layered envelope was II $6 \mathrm{~nm}$ (S.D. I.I9, 9 readings) thick.

The separation of the outer envelope from the protoplasmic cylinder was incomplete (Fig. 6). Removal of the outer envelope by $50 \%$ ethanol treatment did not disrupt the helicoidal structure of the protoplasmic cylinder (Fig. 7).

\section{Electron microscopy of untreated whole Patoc I organisms after reaction with anti-ESS globulin}

Examination under the dark-ground microscope of washed healthy untreated Patoc I organisms that had been reacted with anti-ESS globulin revealed a complete agglutination of the leptospires. Electron microscopy of thin sections of this material revealed that the 


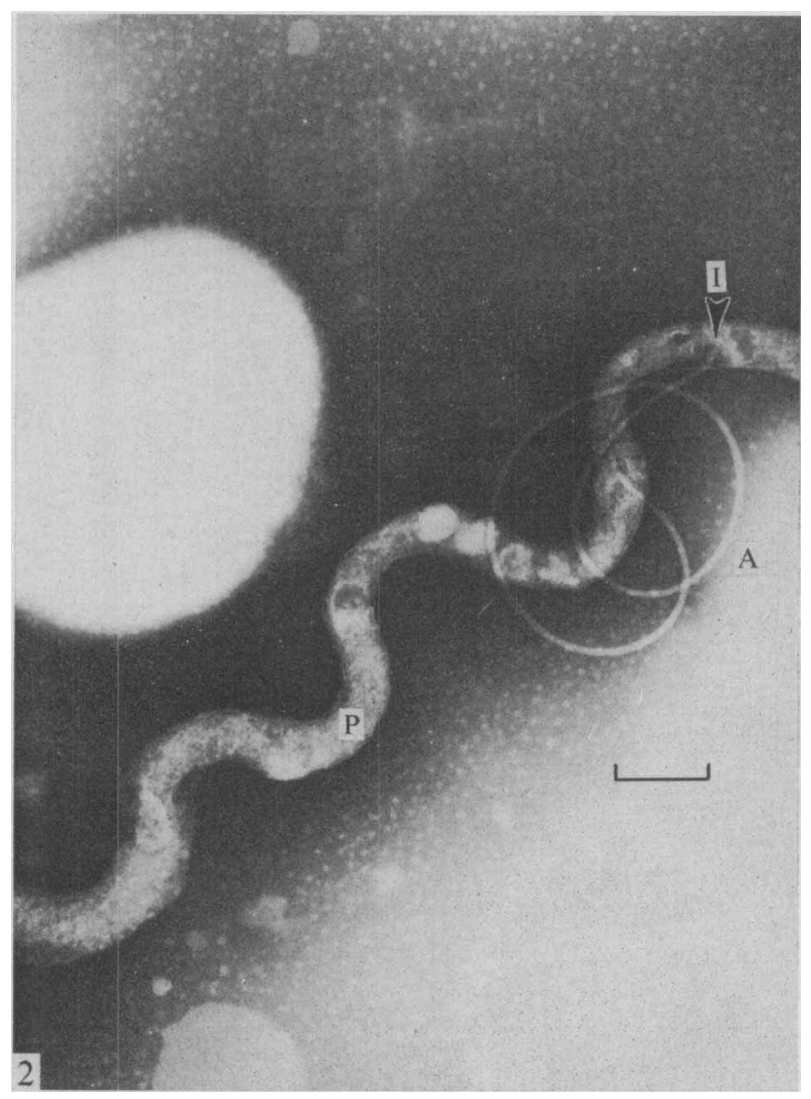

Fig. 2. Electron micrograph of negatively-stained Patoc I organism. The Leptospira has lost the outer envelope. I, point of insertion of the axial filament; $\mathbf{A}$, axial filament; $\mathbf{P}$, protoplasmic cylinder. Bar marker $0.2 \mu \mathrm{m}$.

treatment with anti-ESS globulin had bound the outer envelopes together (Fig. 8). The bound envelopes were separated by a relatively amorphous, electron dense layer of fairly uniform thickness (18.4 $\mathrm{nm}$, S.D. $\mathrm{I} \cdot 86,7 \mathrm{I}$ readings), which we assumed was a layer of antibody molecules. Often the binding together of the outer envelopes, which were separated from the protoplasmic cylinder, was also observed. In Fig. 9 some fourteen to fifteen envelopes are bound together. Some five-layered envelopes $7 \cdot 7 \mathrm{~nm}$ (S.D. $0.82,6$ readings) thick were also evident (Fig. 8).

\section{Electron microscopic structure of $90 \%(v / v)$ ethanol precipitate}

The $90 \%$ ethanol precipitate was composed of numerous membranous structures, and neither the protoplasmic cylinders nor the axial filaments were observed when this material was negatively stained and examined (Fig. IO). In cross-sections this precipitate had the same structure (Fig. II) as the outer envelope of normal untreated leptospires. It was composed of three layers of uniform thickness and its overall thickness was of the same order as that measured for the outer envelope. 


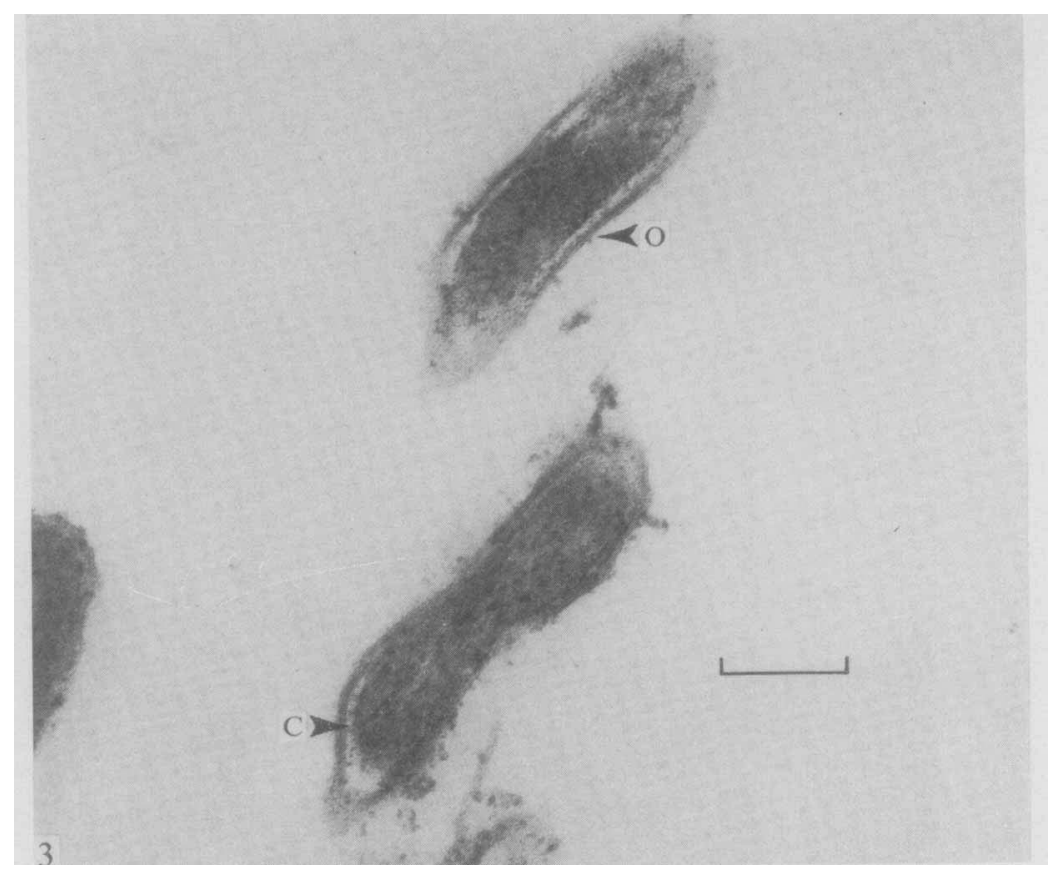

Fig. 3. Electron micrograph of sections of healthy Patoc I organisms. $\mathrm{O}$, triple-layered outer envelope; C, cell wall. Bar marker $0 . \mathrm{I} \mu \mathrm{m}$.

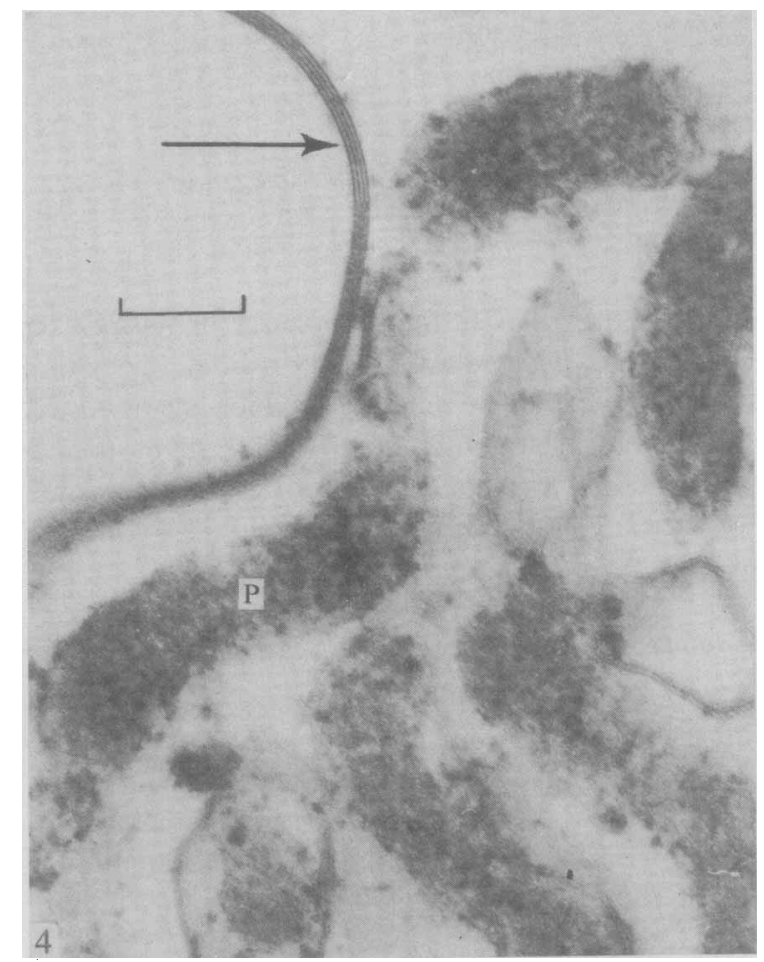

Fig. 4. Electron micrograph of sections of $50 \%(\mathrm{v} / \mathrm{v})$ ethanol-treated Patoc I organism. The arrow indicates the seven-layered outer envelope. P, Protoplasmic cylinder without envelope. Bar marker $0 \cdot 1 \mu \mathrm{m}$. 


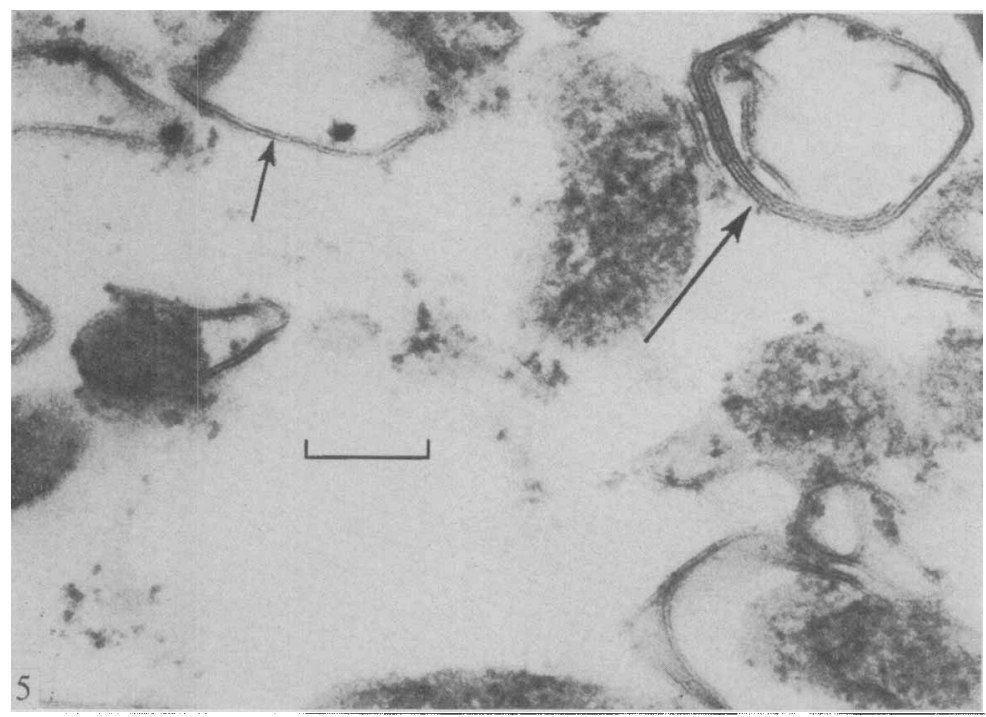

Fig. 5. Electron micrograph of sections of $50 \%(\mathrm{v} / \mathrm{v})$ ethanol-treated Patoc I organism. The large arrow shows the seven-layered outer envelope; the small arrow the triple-layered outer envelope. Bar marker $0.1 \mu \mathrm{m}$.

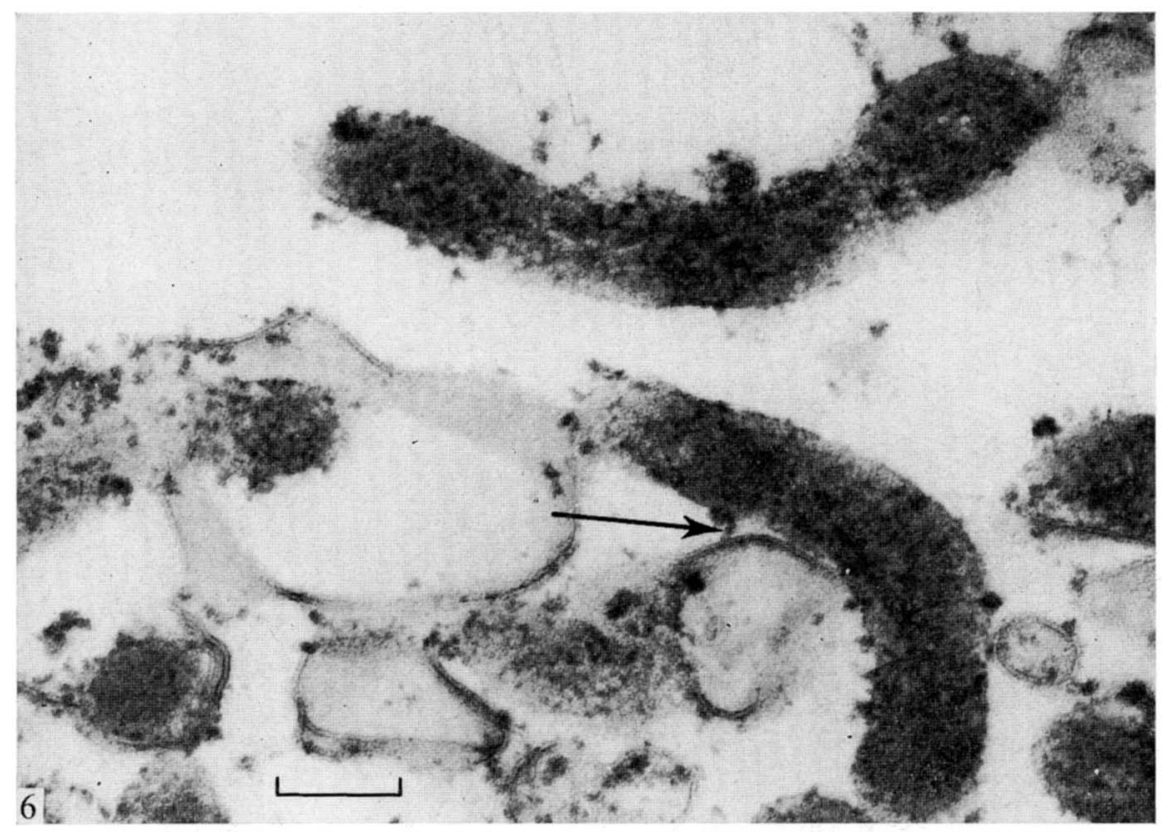

Fig. 6. Electron micrograph of sections of $50 \%(\mathrm{v} / \mathrm{v})$ ethanol-treated Patoc I organisms. The arrow indicates the outer envelope stripped off from the protoplasmic cylinder. Bar marker $0 \cdot 1 \mu \mathrm{m}$. 


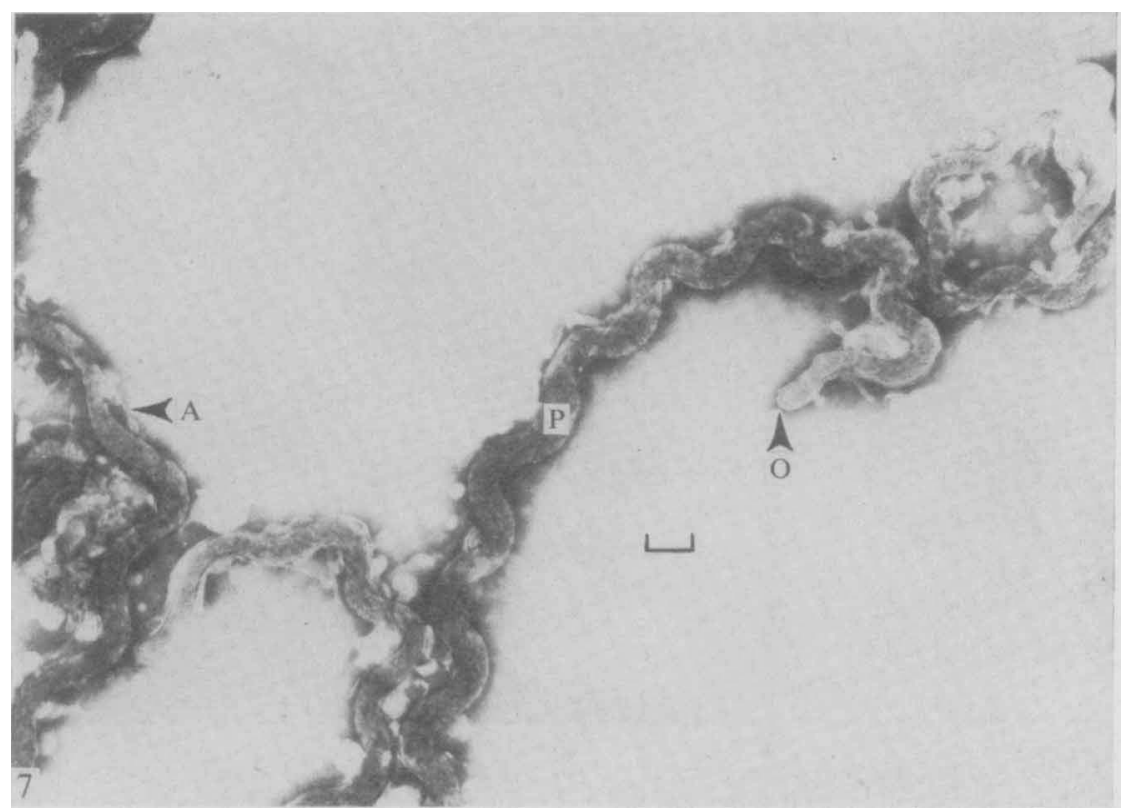

Fig. 7. Electron micrograph of negatively-stained Patoc I organisms after $50 \%(\mathrm{v} / \mathrm{v})$ ethanol treatment. $P$, protoplasmic cylinder; A, axial filament; $O$, outer envelope. Bar marker $0.2 \mu \mathrm{m}$.

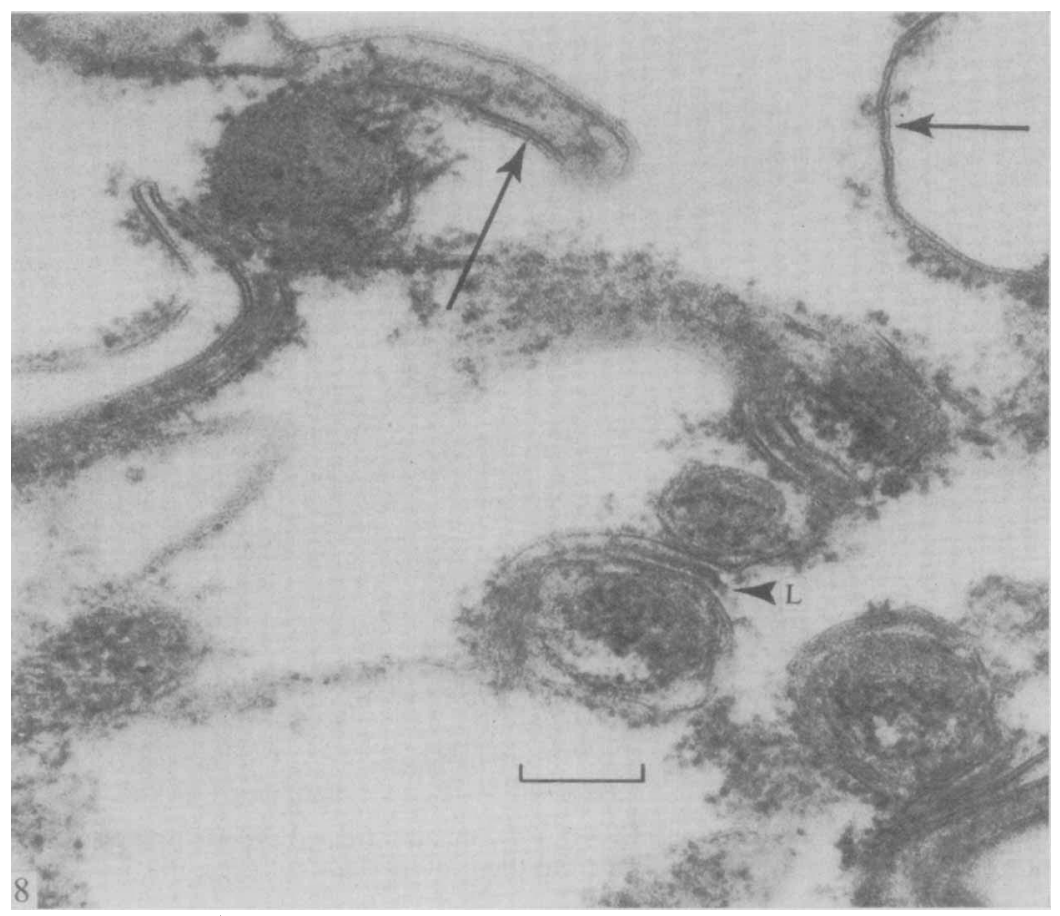

Fig. 8. Electron micrograph of sections of Patoc I organisms after reaction with anti-ESS serum. The arrows show the five-layered outer envelope stripped off from the organism. L, layer ${ }_{5}^{*}$ of antibodies. Bar marker $0.1 \mu \mathrm{m}$. 


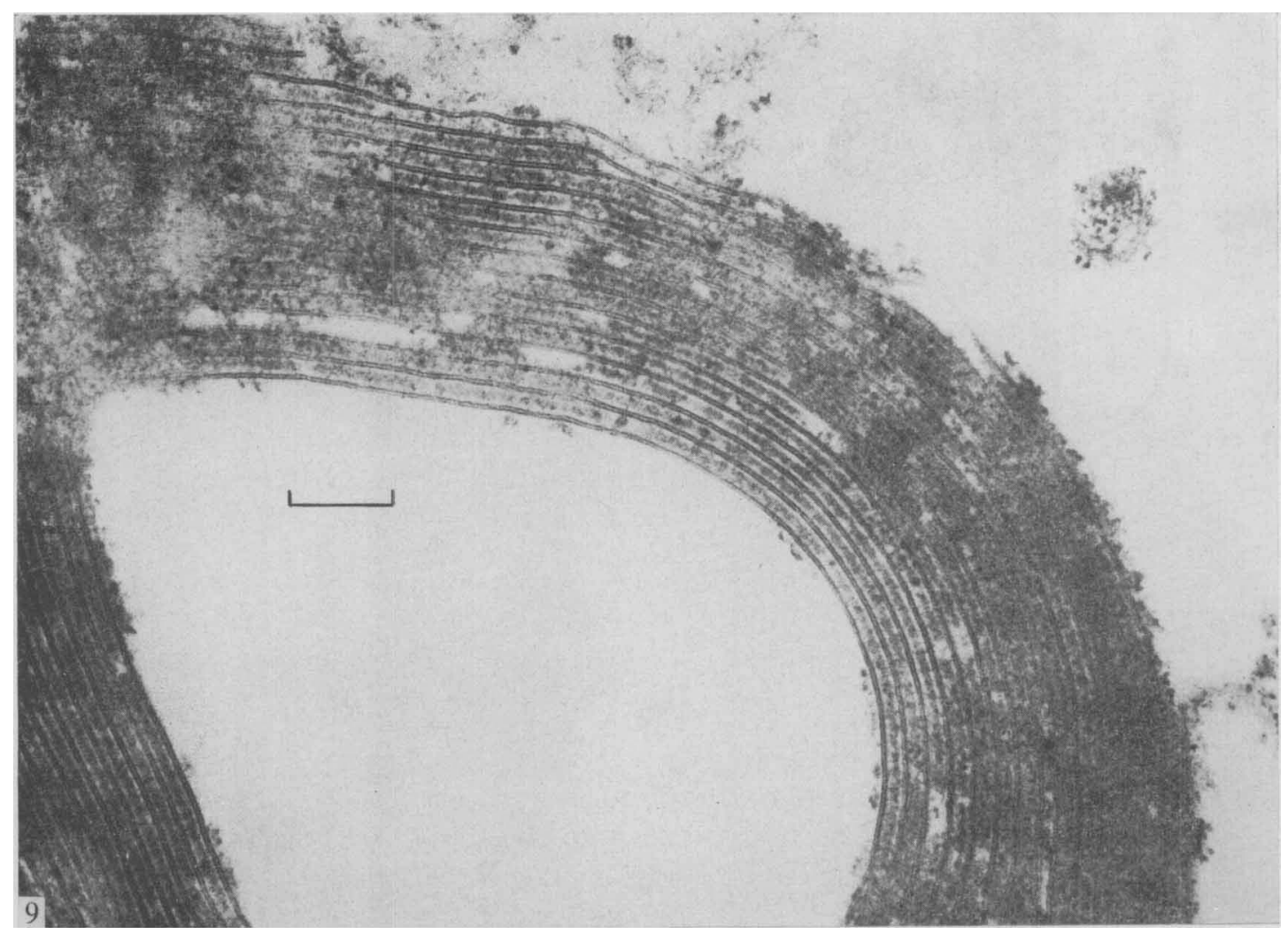

Fig. 9. Electron micrograph of sections of Patoc I organisms after reaction with anti-ESS serum. Agglutination of 14 to 15 triple-layered outer envelopes with dense areas in between the envelopes. Bar marker $0.1 \mu \mathrm{m}$.

\section{Serology}

Absorption studies. Washed live Patoc I cells removed from serum almost all of the specific antibodies responsible for both h.a. and m.a. reactions (Table I), but $50 \%$ (v/v) ethanol treated, washed leptospires removed only part of the h.a. and m.a. antibodies.

Agar gel diffusion test. The $90 \%$ ethanol-precipitated Patoc I antigen showed one precipitin line (Fig. 12) in Ouchterlony's double diffusion agar gel test with anti-ESS serum and with its ammonium sulphate-precipitated fraction.

\section{Chemical analyses on the $90 \%$ ethanol precipitate}

Chemical analyses indicated that the $90 \%$ ethanol precipitate was a glycolipoprotein (Table 2) containing carbohydrate ( 17 to $18 \%$, w/w), lipid ( 13 to $18 \%$, w/w), amino sugar $(0.5 \%, w / w)$, protein $(4 \%, w / w)$ and a trace of phosphorus.

Sugar composition. Paper chromatographic analysis of the $\mathrm{H}_{2} \mathrm{SO}_{4}$ and the $\mathrm{HCl}$ hydrolysates of the ethanol precipitate suggested that the neutral sugars present were galactose, mannose, xylose and rhamnose.

Amino sugar and amino acid analyses. The $90 \%$ ethanol precipitate of Patoc I contained I6 different amino acids (Table 3). Tryptophan was not determined in this study. Two unidentified peaks were noted on the amino acid analysis chart. One of these ran just 


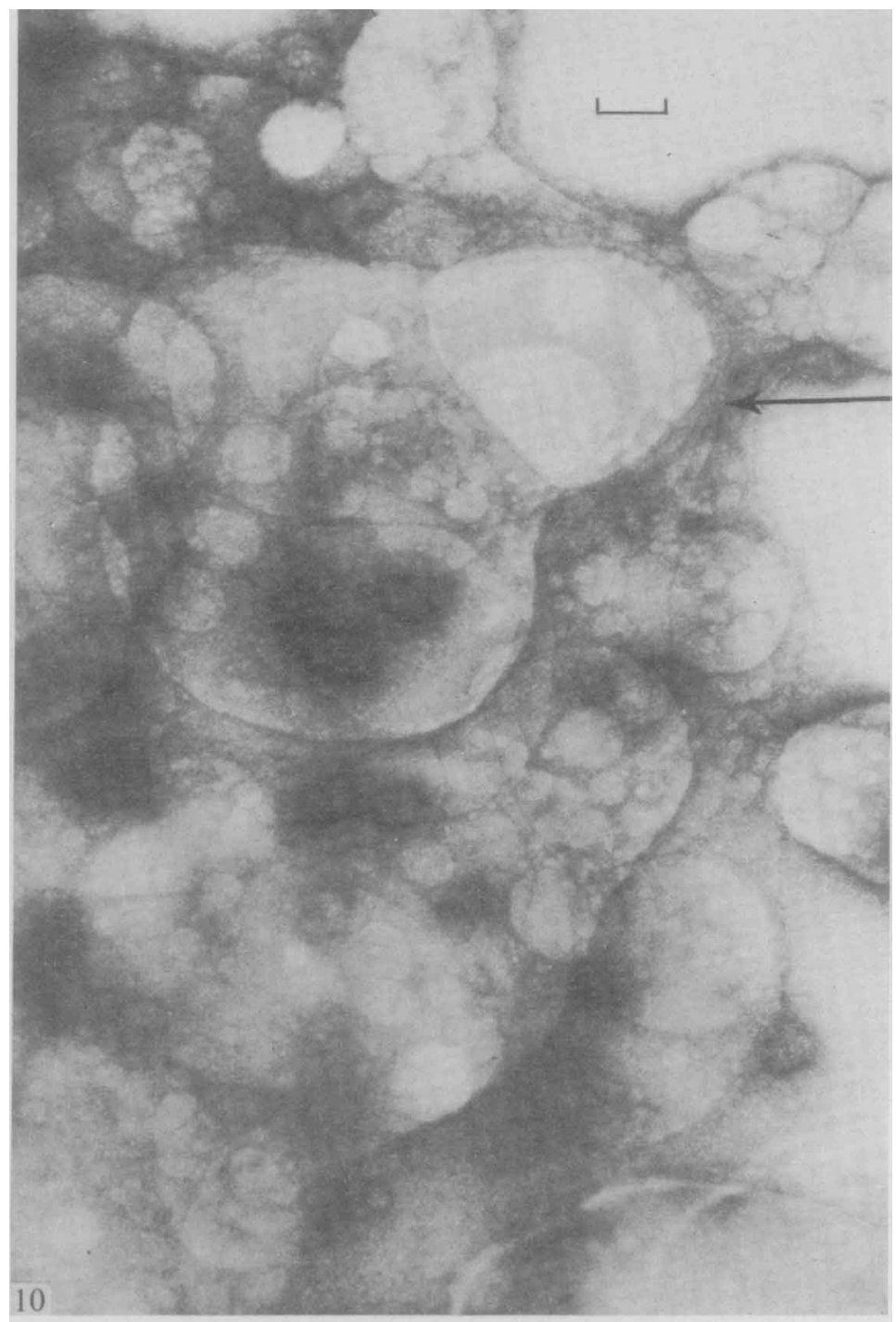

Fig. Io. Electron micrograph of negatively-stained $90 \%(\mathrm{v} / \mathrm{v})$ ethanol precipitate of Patoc I. The arrow indicates layers of membranous outer envelope. Bar marker $0 \cdot 1 \mu \mathrm{m}$.

ahead of lysine, the other was just after ammonia. The amino sugars detected were glucosamine and galactosamine. No muramic acid was detected.

\section{DISCUSSION}

Ultrastructural evidence indicated that $50 \%$ ethanol treatment of strain Patoc I removed most of the outer envelope. Membranes of the same thickness as outer envelopes were recovered from the $90 \%$ ethanol-precipitated material. Such ethanol-extracted and -precipitated material contained erythrocyte-sensitizing substance (ESS). Neither the morphological identification of ESS of Patoc I nor its chemical nature has been reported 


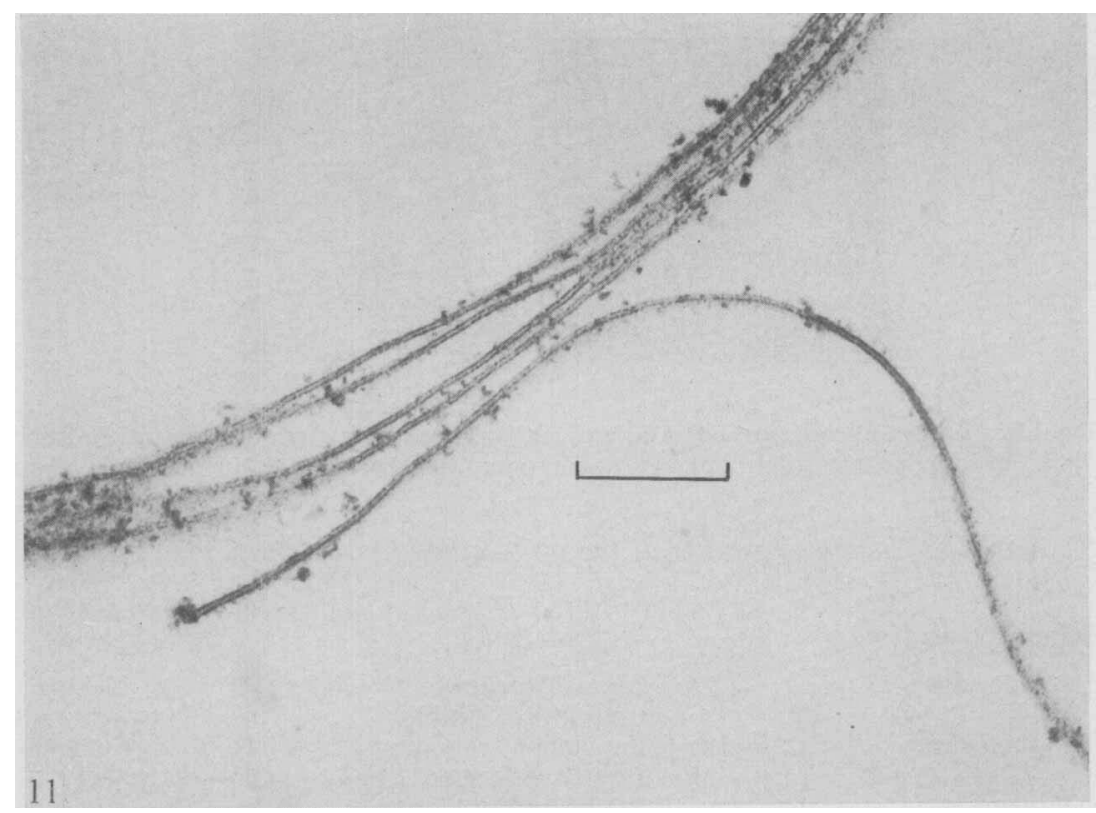

Fig. I I. Electron micrograph of sections of $90 \%(v / v)$ ethanol-precipitated substance of Patoc I organism showing triple-layered outer envelope. Bar marker $0 \cdot 1 \mu \mathrm{m}$.

\section{Table I. Absorption experiments}

Absorption performed by adding $0.9 \mathrm{ml}$ Patoc I suspension containing $8 \times 10^{9}$ organisms $/ \mathrm{ml}$ (in both cases) to $0.1 \mathrm{ml}$ serum.

\section{Anti-ESS serum}

\section{Original (unabsorbed)}

Absorbed with washed, live Patoc I

Absorbed with ethanol (50\% v/v)-treated, washed Patoc I

\begin{tabular}{|c|c|}
\hline \multicolumn{2}{|c|}{ Homologous titres } \\
\hline M.a. test & H.a. test \\
\hline $\begin{array}{c}\text { I : }: 320 \\
\text { Nil }\end{array}$ & $\begin{array}{l}1: 320 \\
1: 10^{*}\end{array}$ \\
\hline $1: 40$ & I : 40 \\
\hline
\end{tabular}

* Doubtful reaction.

before. Electron microscopic study revealed that rabbit anti-ESS Patoc I antiserum caused stripping off and binding together of the outer envelopes of washed, healthy Patoc I organisms. No other part of the leptospira was altered. In between the agglutinated outer envelopes, whether they were separated from the protoplasmic cylinder or not, a layer of electron dense material $18 \cdot 4 \mathrm{~nm}$ thick was found. No such layer was present in the ultrathin sections of the $90 \%$ ethanol-precipitated envelope material. Thus circumstantial evidence suggests that the sandwiched material referred to above was most likely to be a layer of antibodies. All our results suggest that the genus-specific $90 \%$ ethanol precipitate is the outer envelope of Patoc I. Partial removal of the outer envelope of leptospires by $50 \%$ ethanol treatment has also been reported by Yanagawa \& Faine (1966).

There is no unanimous agreement about the number of layers present in the outer envelope of leptospira (World Health Organization, 1972). Our findings are in agreement with previous reports (Nauman et al. 1969; Anderson \& Johnson, I968; Ritchie \& 

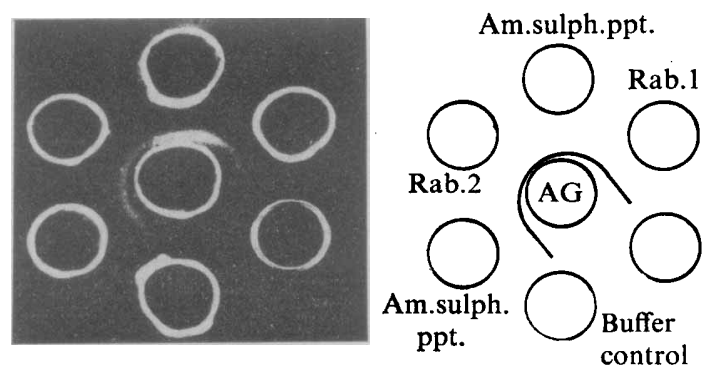

Fig. 12. Double diffusion test in agar gel. AG, $90 \%$ ethanol precipitate; Rab. 1, 2, anti-ESS serum from two different rabbits; Am. sulph. ppt., $33 \%$ ammonium sulphate precipitate of anti-ESS serum.

Table 2. Chemical aspects of the $90 \%$ ethanol precipitate of Patoc I

Compound analysed
Amino sugar
Lipid
Carbohydrate
Protein
Phosphorus

Method

Composition

Elson-Morgan

Chloroform soluble

Indole test

Ferricyanide test

Micro-Kjeldahl

Modified phospho-

molybdate method
$(\%, w / w)$

$0.52 \pm 0.02$

13.5 to 18.5

$17 \cdot 6 \pm 0.6$

$17 \cdot 8 \pm 2$

$4 \cdot I$

Trace amount

Table 3. Amino acid and amino sugar analyses of the $90 \%$ ethanol precipitate of Patoc I organisms

\begin{tabular}{lc}
$\begin{array}{c}\text { Amino acid } \\
\text { or amino sugar }\end{array}$ & $\begin{array}{c}\text { Concentration* } \\
(\mu \mathrm{mol} / \mathrm{ml}) \\
\text { Ammonia }\end{array}$ \\
Lysine & 0.09 \\
Histidine & 0.76 \\
Arginine & 0.09 \\
Aspartic & 0.17 \\
Threonine & 0.67 \\
Serine & 0.32 \\
Glutamic & 0.41 \\
Proline & 0.82 \\
Glycine & 0.33 \\
Alanine & 0.69 \\
Valine & 0.61 \\
Methionine & 0.39 \\
lsoleucine & 0.11 \\
Leucine & 0.28 \\
Tyrosine & 0.47 \\
Phenylalanine & 0.15 \\
Glucosamine & 0.22 \\
Galactosamine & 0.14 \\
Unidentified compounds: & 0.006 \\
Just ahead of lysine & 0.098 \\
Just after ammonia & 0.01 \\
\multicolumn{2}{c}{$* \pm 5 \%}$. \\
\end{tabular}


Ellinghausen, 1965) that the outer envelope is mostly triple layered but we observed some 5- (7.7 $\mathrm{nm}$ thick) and 7-layered (I I.8 nm thick) envelopes. Anderson \& Johnson (I968) also observed five layers in the outer envelope of Patoc $I$.

The absence of muramic acid in the ethanol-precipitated material suggested that the outer envelope we isolated from Patoc I was free of cell wall material. The presence of other cellular components, if any, has not been investigated.

Shinagawa \& Yanagawa (1972) reported the results of chemical analysis of a type-specific (TM) antigen they extracted by a $90 \%$ phenol extraction procedure from strain Kyoto of the hebdomadis serogroup. This TM antigen contained the same three sugars which we found in the Patoc I outer envelope antigen, namely galactose, xylose and rhamnose, but their antigen additionally contained arabinose whereas ours had mannose instead. Galactosamine and glucosamine were present in the outer envelope of Patoc I, but the TM antigen from the strain Kyoto contained only glucosamine. The amino acid content of the TM antigen differed considerably from that of the outer envelope of Patoc I. The sugar composition which we observed in the genus-specific Patoc I outer envelope antigen also differed from the alkali-extracted serotype-specific polysaccharide of Patoc I antigen as reported by Faine, Adler, Ruta \& Palit (1972). While the latter antigen contained glucosamine, galactosamine, galactose, glucose, mannose, ribose and rhamnose (Faine et al. I972), no glucose or ribose was found in the genus-specific antigen which contained xylose as an additional sugar. All these findings lead to the conclusion that a definite chemical difference exists between the type-specific and genus-specific antigens from leptospires.

We are grateful to D. J. Evans for carrying out the amino acid analysis and to J. Birner for his help in chemical analyses. Acknowledgements are also due to W. Finger for statistical analysis, V. Draffin for photography and to Mrs C. Rodda and R. Sikkes for excellent technical assistance.

\section{REFERENCES}

Alston, J. M. \& Broom, J. C. (1958). Culture media and laboratory techniques. In Leptospirosis in Man and Animals, p. 303. Edinburgh and London: E. \& S. Livingstone.

ANDERSON, D. L. \& JoHNSON, R. C. (1968). Electron microscopy of immune disruption of leptospires: action of complement and lysozyme. Journal of Bacteriology 95, 2293-2309.

Auran, N. E., Johnson, R. C. \& RITZI, D. M. (1972). Isolation of the outer sheath of Leptospira and its immunogenic properties in hamsters. Infection and Immunity 5, 968-975.

CARPENTER, P. L. (1965). Experiments in serology. In Immunology and Serology, 2nd edn, p. 424. Philadelphia and London: Saunders.

Chang, A. \& FaINe, S. (1970). Electron-microscopic evidence for reactions of axial filaments of Leptospira with IgM and IgG antibodies. Bulletin of the World Health Organization 43, 57I-577.

ChANG, R. S. M. \& MCCoMB, D. E. (1954). Erythrocyte sensitizing substance (ESS) from five strains of leptospirae. American Journal of Tropical Medicine and Hygiene 3, 48I-489.

Faine, S., Adler, B., Ruta, G. \& Palit, A. (1972). A specific polysaccharide from Leptospira related to immunity in leptospirosis. Journal of General Microbiology 71, vii-viii.

KABAT, E. A. \& MAYER, M. M. (1964a). Ammonium sulphate fractionation. In Experimental Immunochemistry, and edn, pp. 762-763. Springfield, Illinois: Charles C. Thomas.

KABAT, E. A. \& MAYER, M. M. (1964b). Carbohydrate estimation. In Experimental Immunochemistry, 2nd edn, pp. 527-528. Springfield, Illinois: Charles C. Thomas.

KABAT, E. A. \& MAYER, M. M. (1964c). Hexosamine and $N$-acetyl hexosamine estimation. In Experimental Immunochemistry, 2nd edn, pp. 504-507. Springfield, Illinois: Charles C. Thomas.

Kellenberger, E., RYTER, A. \& SéCHAUd, J. (1958). Electron microscope study of DNA-containing plasms. II. Vegetative and mature phage DNA as compared with normal bacterial nucleoids in different physiological states. Journal of Biophysical and Biochemical Cytology 4, 671-678. 
LindBerg, O. \& ERNSTER, L. (1956). Determination of organic phosphorus compounds by phosphate analysis. Methods of Biochemical Analysis 3, 7.

Nauman, R. K., Holt, S. C. \& Cox, C. D. (1969). Purification, ultrastructure, and composition of axial filaments from Leptospira. Journal of Bacteriology 98, 264-280.

Paltt, A. \& Gulasekharam, J. (1973). Genus-specific leptospiral antigen and its possible use in laboratory diagnosis. Journal of Clinical Pathology 26, 7-16.

Palit, A. \& Sharma, G. L. (197I). Comparison of microscopic agglutination, indirect haemagglutination and complement-fixation tests in rabbit and buffalo-calf hyperimmune sera for detection of leptospiral antibodies. British Veterinary Journal 127, 154-162.

PaRK, J. T. \& Johnson, M. J. (1949). A submicrodetermination of glucose. Journal of Biological Chemistry I8I, I49-I5I.

PiLLot, J. \& RYTER, A. (1965). Structure des spirochètes. I. Étude des genres Treponema, Borrelia et Leptospira au microscope electronique. Annales de l'Institut Pasteur 108, 791-804.

REYNOLDS, E. S. (1963). The use of lead citrate at high pH as an electron-opaque stain in electron microscopy. Journal of Cell Biology 17, 208-212.

Ritchie, A. E. \& Ellinghausen, H. C. (1965). Electron microscopy of leptospires. I. Anatomical features of Leptospira pomona. Journal of Bacteriology 89, 223-233.

Shinagawa, M. \& YanaGawa, R. (1972). Isolation and characterization of a leptospiral type-specific antigen. Infection and Immunity 5, I2-19.

Sмiтн, I. (1960). Sugars. In Chromatographic and Electrophoretic Techniques, vol. I, 2nd edn, pp. 246-260. Edited by I. Smith. London: William Heineman Medical.

Williams, C. A. \& Chase, M. W. (1968). Carbohydrate analysis. a. Submicro method. In Methods in Immunology and Immunochemistry, vol. 2, pp. 284-285. New York and London: Academic Press.

World Health Organization (1972). Memoranda. Research needs in leptospirosis. Bulletin of the World Health Organization 47, $113-122$.

YANAGAWA, R. \& FAINE, S. (1966). Morphological and serological analysis of leptospiral structure. Nature, London 21X, 823-826. 